\title{
Inverted papilloma of the urinary bladder: a molecular genetic appraisal
}

\author{
Ming-Tse Sung ${ }^{1,2}$, John N Eble ${ }^{1}$, Mingsheng Wang ${ }^{1}$, Puay-Hoon Tan ${ }^{3}$, \\ Antonio Lopez-Beltran ${ }^{4}$ and Liang Cheng ${ }^{1,5}$ \\ ${ }^{1}$ Department of Pathology and Laboratory Medicine, Indiana University School of Medicine, Indianapolis, IN, \\ USA; ${ }^{2}$ Department of Pathology, Chang Gung Memorial Hospital-Kaohsiung Medical Center and Chang Gung \\ University College of Medicine, Kaohsiung, Taiwan; ${ }^{3}$ Department of Pathology, Singapore General Hospital, \\ Singapore; ${ }^{4}$ Department of Pathology, Cordoba University, Cordoba, Spain and ${ }^{5}$ Department of Urology, \\ Indiana University School of Medicine, Indianapolis, IN, USA
}

\begin{abstract}
Inverted papilloma of urinary bladder is an uncommon urothelial neoplasm. Its relationship to urothelial carcinoma is controversial. Little is known of the genetic abnormalities of inverted papilloma. To better understand its genetics, we analyzed 39 inverted papillomas, including 36 from men and three from women, for loss of heterozygosity (LOH). We examined four polymorphic microsatellite markers located on chromosome 9q32-33(D9S177), chromosome 9p22 (IFNA), chromosome 3p14.2 (D3S1300) and chromosome 17p13.1 (TP53), where genetic alterations occur frequently in urothelial carcinomas. Additionally, the status of inactivation of $\mathrm{X}$-chromosome was examined in three female patients. The frequency of $\mathrm{LOH}$ in informative cases was $8 \%$ (3 of 37) for D9S177, 10\% (4 of 38) for TP53, 8\% (3 of 37) for IFNA and 8\% (3 of 36) for D3S1300. In the analysis of $\mathrm{X}$-chromosome inactivation, all three cases yielded informative results and one had nonrandom inactivation of X-chromosomes. The monoclonal origin demonstrated in the study of X-chromosome inactivation indicates the clonal process of inverted papilloma; however, the low incidence of LOH supports the view that inverted papilloma in urinary bladder is a benign neoplasm with molecular genetic abnormalities different from those of urothelial carcinoma.
\end{abstract}

Modern Pathology (2006) 19, 1289-1294. doi:10.1038/modpathol.3800667; published online 21 July 2006

Keywords: urinary bladder; neoplasia; inverted papilloma; loss of heterogosity; X-chromosome inactivation; clonality

Inverted papilloma urinary bladder is an uncommon urothelial neoplasm of which makes up $<1 \%$ of all urothelial neoplasms. ${ }^{1}$ While it is generally regarded as a benign neoplasm, conflicting data on recurrence rate and association with synchronous and metachronous urothelial carcinoma have left uncertainties concerning the relationship of inverted papilloma with urothelial carcinoma. ${ }^{2-10}$

Oncogene activation and tumor suppressor gene inactivation are important mechanisms in the genesis, propagation and spread of urothelial carcinoma. ${ }^{1-19}$ However, little or nothing is known of the molecular genetic events in the development of inverted papilloma of the urinary bladder. This

Correspondence: Dr L Cheng, MD, Department of Pathology and Laboratory Medicine, Indiana University School of Medicine, 350 West 11th Street, Clarian Pathology Laboratory Room 4010, Indianapolis, IN 46202, USA.

E-mail: Icheng@iupui.edu

Received 3 May 2006; revised and accepted 23 June 2006; published online 21 July 2006 study was conducted to investigate genetic alterations in inverted papilloma by evaluating the prevalence of losses of heterozygosity ( $\mathrm{LOH}$ ), which are common in urothelial carcinoma and to analyze the X-chromosome inactivation status in inverted papilloma.

\section{Materials and methods}

\section{Patients}

Inverted papillomas in the urinary bladder were retrieved from the surgical pathology archives of the Departments of Pathology of Indiana University (Indianapolis, IN, USA), Cordoba University (Corboda, Spain), Chang Gung Memorial Hospital (Kaohsiung, Taiwan) and Singapore General Hospital (Singapore) between 1986 and 2004. All slides were retrospectively reviewed and diagnosed according to the accepted criteria. ${ }^{1}$ Patients with insufficient tissue specimens for genetic analysis were excluded. Thirty-nine cases, including 36 from 
men and three from women, fulfilled the requirement were selected into this study.

\section{Tumor Samples and Microdissection}

Histological sections were prepared from formalinfixed, paraffin-embedded blocks and stained with hematoxylin and eosin for histological examination and microdissection. Genomic DNA was prepared from tumor cells of inverted papilloma, microdis-
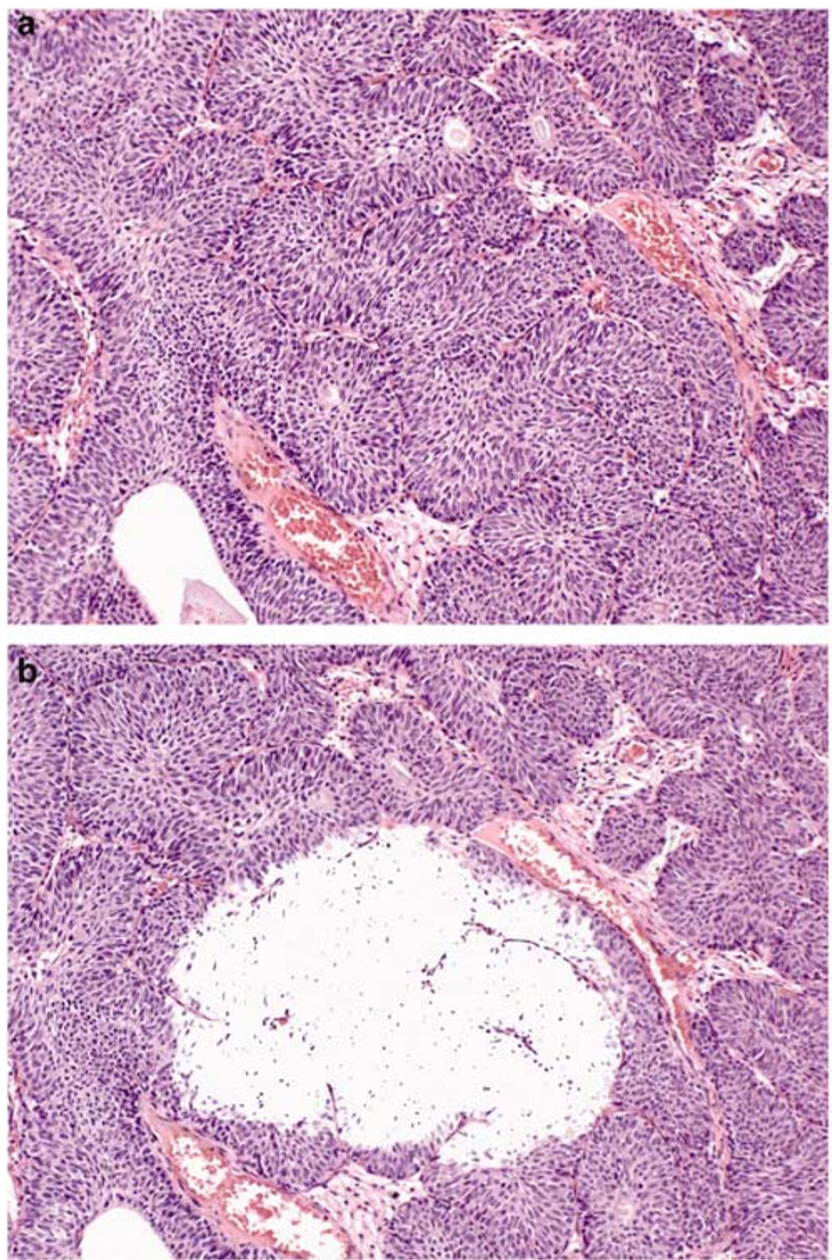

C

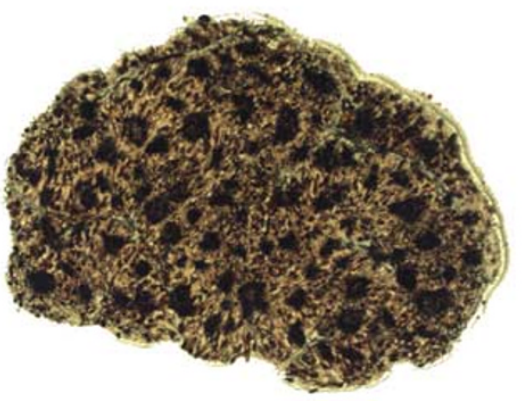

Figure 1 Laser capture microdissection of inverted papilloma in urinary bladder. (a) Tumor specimen before microdissection. (b) Tumor specimen after microdissection. (c) Laser-captured tumor cells. sected by the PixCell II laser capture microdissection system (Arcturus, Mountain View, CA, USA), as previously described (Figure 1). ${ }^{20-22}$ Approximately 400-600 cells were microdissected from $5-\mu \mathrm{m}$ histologic sections. Normal tissues microdissected from the same specimen were used as a control sample for each patient.

\section{Detection of LOH}

The following four oligonucleotide primer pairs for microsatellite DNA markers were chosen on the basis of their frequent alteration in urothelial carcinoma and papillary urothelial neoplasm of low malignant potential: D3S1300 (chromosome 3p14.2), IFNA (chromosome 9p22), D9S177 (chromosome 9q32-33) and TP53 (chromosome 17p13.1). ${ }^{11,13,14,18,21,23,24}$ Polymerase chain reaction (PCR) and gel electrophoresis were performed for all 39 cases, as previously described. ${ }^{20,25,26} \mathrm{LOH}$ was determined by a combination of direct visualization and scanning densitometry of the autoradiograms with a phosphorimager (Molecular Dynamics Inc., Sunnyvale, CA, USA). The criterion for allelic loss was complete or near complete absence of one allele in tumor DNA as previously described ${ }^{25-27}$ PCRs for each polymorphic microsatellite marker were repeated at least twice from the same DNA preparations, and the same results were obtained. The results were reported as noninformative when two distinct bands could not be distinguished in control DNA after PCR amplification.

\section{Detection of X-Chromosome Inactivation}

$\mathrm{X}$-chromosome analysis was performed in the three tumors from women. The microdissected tissues were placed in $50 \mu \mathrm{l}$ of buffer $(10 \mathrm{mM}$ Tris, $1 \mathrm{mM}$ EDTA, $1 \%$ Tween-20 and $5 \mathrm{mg} / \mathrm{ml}$ proteinase $\mathrm{K}(\mathrm{pH}$ 8.3)) and incubated overnight at $37^{\circ} \mathrm{C}$ for DNA extraction. ${ }^{26,28}$ Eight microliter aliquots of the DNA extract were digested overnight with $1 \mathrm{U}$ of $\mathrm{HhaI}$ restriction endonuclease (New England Biolabs Inc., Beverly, MA, USA) in a total volume of $10 \mu \mathrm{l}$. Control reactions for each sample were incubated in the digestion buffer without HhaI endonuclease. Primers used in this reaction were: AR-sense: $5^{\prime}$ TCC AGA ATC TGT TCC AGA GCG TGC3' and ARantisense: 5'GCT GTG AAG GTT GCT GTT CCT CAT3 $^{\prime}$. Polymerase chain reaction and gel electrophoresis were performed as described. ${ }^{26,28}$

The clonality of the samples was evaluated on the basis of a polymorphism of the X-linked human androgen receptor gene (HUMARA) locus. ${ }^{26,28-30}$ This technique is dependent on digestion of DNA with the methylation-sensitive restriction enzyme HhaI, PCR amplification of the HUMARA locus and the detection of methylation at this locus. With this method, only the methylated HUMARA allele is amplified by PCR. The random inactive status of an 
$\mathrm{X}$ chromosome is established in all female somatic cells early in embryogenesis. ${ }^{31}$ Normal female tissues should be a cellular mosaic, with an equal distribution of cells containing maternal or paternalderived inactivated $\mathrm{X}$ chromosomes. Nonrandom $\mathrm{X}$ chromosome inactivation indicates a clonal process. ${ }^{29}$

The cases were considered informative if the control sample displayed two alleles after PCR amplification without HhaI digestion. Nonrandom inactivation of the $\mathrm{X}$ chromosomes was defined as a complete or nearly complete absence of one or the other allele after HhaI digestion, indicating predominance of one androgen receptor allele.

\section{Results}

We analyzed LOH in 39 inverted papillomas, including 36 from men and three from women, as well as X-chromosome inactivation status in the three tumors from women (Figure 2). In the study of $\mathrm{LOH}$, the pattern was informative for 37 tumors $(95 \%)$ at the D9S199 locus, 38 patients $(97 \%)$ at the
TP53 locus, 37 patients (95\%) at the IFNA locus and 36 patients $(92 \%)$ at the D3S1300 locus. The frequency of $\mathrm{LOH}$ in informative cases was $8 \%$ (3 of 37) for D9S177, 10\% (4 of 38) for TP53, 8\% (3 of 37) for IFNA and 8\% (3 of 36) for D3S1300. Among the tumors demonstrating $\mathrm{LOH}$, one of them (case 2) revealed LOH in two loci (TP53 and D3S1300) and the remaining tumors showed loss of allele in only one locus. None of normal tissues showed $\mathrm{LOH}$ in this study.

The tumors from the three women were examined by X-chromosome inactivation analysis. All three cases yielded informative results. Nonrandom inactivation of X-chromosomes was identified in one tumor (case 39), while random inactivation of X-chromosomes was identified in the other two (case 19 and 25).

\section{Discussion}

In our study of inverted urothelial papilloma analyzed by LOH and X-chromosome inactivation, both the low incidence of $\mathrm{LOH}$ and nonrandom.

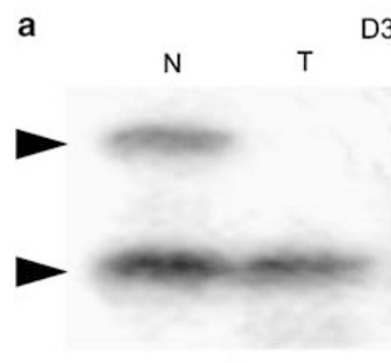

2

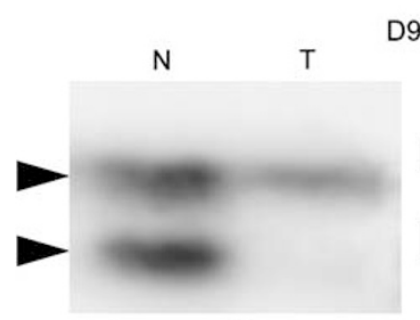

10
D3S1300
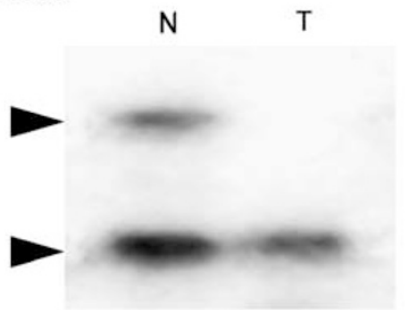

33

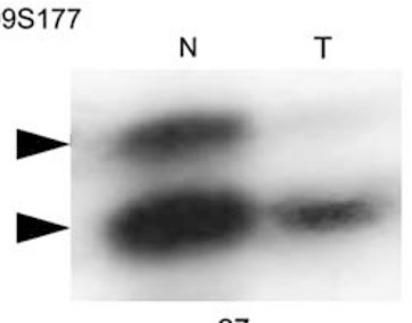

27

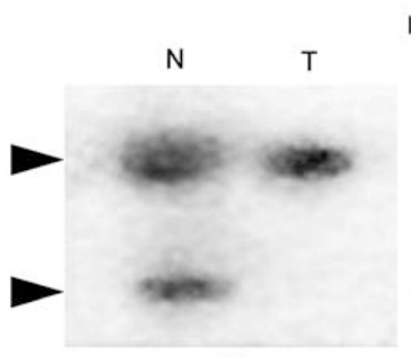

11
IFNA

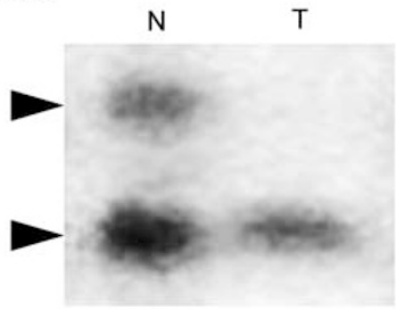

32

22

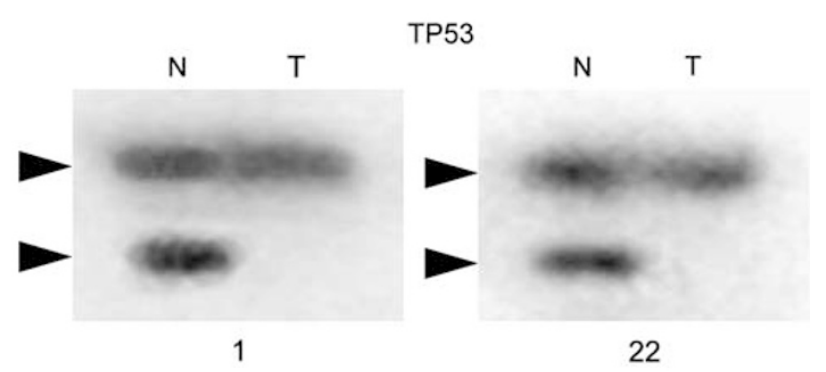

b
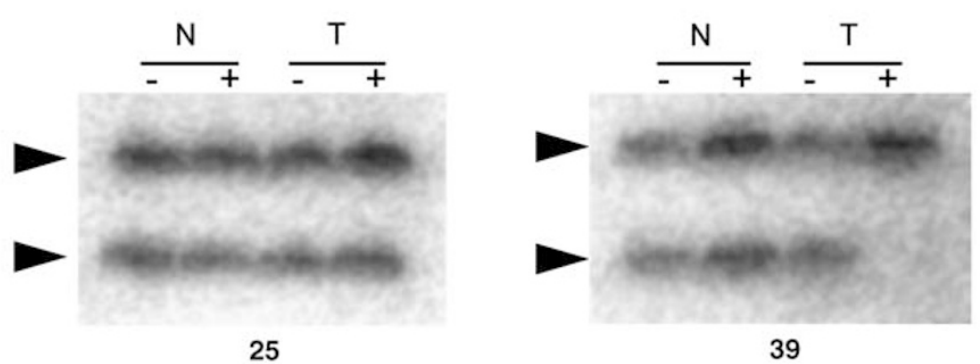

Figure 2 Representative results of LOH (a) and X-chromosome inactivation analysis (b) in inverted papilloma of the urinary bladder. In panel a, DNA was prepared from normal and tumor tissue, amplified by polymerase chain reaction using polymorphic markers D3S1300, IFNA, D9S177 and TP53 and separated by gel electrophoresis. In panel b, nonrandom inactivation of X-chromosome was identified in case 39. Arrows: allelic bands, N: normal control tissue, T: tumor tissue of inverted papilloma, -: without Hhal endonuclease digestion, + : with Hhal endonuclease digestion. 
Table 1 Comparison of LOH between inverted papilloma, papillary urothelial neoplasm of low malignant potential and urothelial carcinoma

\begin{tabular}{|c|c|c|c|c|c|}
\hline \multirow[t]{2}{*}{ Reference } & \multirow[t]{2}{*}{ Specimen } & \multicolumn{4}{|c|}{ Frequency of LOH (\%) chromosome region } \\
\hline & & D9S177 9q32-33 & IFNA $9 p 22$ & TP53 17p13.1 & D3S1300 3p14.2 \\
\hline Current study & Inverted papilloma & 8 & 8 & 10 & 8 \\
\hline Cheng et $a l^{21}$ & PUNLMP & 41 & 32 & 29 & 44 \\
\hline Baud et $a l^{11}$ & Urothelial carcinoma & 74 & & & \\
\hline Paterson et $a l^{23}$ & Urothelial carcinoma & 67 & & 47 & \\
\hline Keen et $a l^{13}$ & Urothelial carcinoma & & 60 & & \\
\hline Uchida et $a l^{24}$ & Urothelial carcinoma & & 35 & 39 & \\
\hline Primdahl et $a l^{18}$ & Urothelial carcinoma & & 35 & 41 & \\
\hline Louehelainen et $a l^{14}$ & Urothelial carcinoma & & & & 80 \\
\hline
\end{tabular}

LOH: loss of heterozygosity; PUNLMP: papillary urothelial neoplasm of low malignant potential.

X-chromosome inactivation support the notion that inverted papilloma in urinary bladder is a benign urothelial neoplasm, lacking the molecular genetic abnormalities typical of urothelial carcinomas.

Cheng et $a l^{32}$ reviewed the English-language literature, including 302 inverted papillomas in the lower urinary tract, and found that the recurrence rate was $4 \%$ and the incidences of associated synchronous urothelial carcinoma and development of subsequent urothelial carcinoma was 6 and $3 \%$, respectively. Overaccumulation of p53 protein, overexpression of HER-2/neu and increased proliferative index have been identified in inverted papillomas, raising the possibility that it might have the potential for future malignant transformation. ${ }^{4,9}$ Amin et $a l^{33}$ reported that urothelial carcinoma with an inverted growth pattern may have features resembling inverted papilloma and they considered reports of the 'coexistence' of inverted papilloma and urothelial carcinoma to be examples of urothelial carcinoma with inverted architecture. In a study of 11 inverted urothelial papillomas with atypia by Broussard et $a l,{ }^{3}$ they concluded that those cases reported as 'inverted papilloma with malignant features' were best classified as either urothelial carcinoma with inverted pattern or inverted papilloma with atypia.

Recent advances in molecular genetics have shown that urothelial carcinoma arises from the accumulation of genetic alterations in oncogenes and tumor suppressor genes. ${ }^{15-17,19}$ Herein we studied the status of $\mathrm{LOH}$ in inverted papilloma using four microsatellite markers, which commonly are altered in urothelial carcinomas. ${ }^{11,13,14,18,21,23,24}$ Our results are compared with those of the previous studies in Table 1 . The incidence of $\mathrm{LOH}$ in inverted papilloma is low (8-10\%) and contrasts with the high frequency of LOH $(29-80 \%)$ in urothelial carcinomas and papillary urothelial neoplasms of low malignant potential. ${ }^{11,13,14,18,21,23,24}$ The low incidence of $\mathrm{LOH}$ in inverted papilloma is similar to the one in normal urothelium, in which Junker et $a l^{34}$ reported that $6 \%$ cases with benign prostatic hyperplasia demonstrated microsatellite alteration on chromosome 9 in their normal urothelial tissue. The opposite expression of LOH between inverted papilloma and urothelial carcinoma may suggest that inverted papilloma usually does not harbor the key genetic changes common in urothelial carcinoma and both entities probably have their own distinct pathogenetic mechanism.

In an investigation to examine $\mathrm{LOH}$ patterns in papillary urothelial hyperplasia and urothelial papilloma, Chow et al ${ }^{35}$ found eight of 15 (53\%) cases of papillary urothelial hyperplasia were clonal, demonstrating $\mathrm{LOH}$ of at least one marker. Additionally, an identical pattern of $\mathrm{LOH}$ between papillary urothelial hyperplasia and subsequently recurrent urothelial carcinoma was identified in one patient. In contrast, none of four papillomas revealed any genetic alteration among the $\mathrm{LOH}$ markers tested. Their molecular data suggested that papillary urothelial hyperplasia may be a precursor lesion of urothelial carcinoma, but there was no genetic evidence to support the precursor nature of papilloma. Neither urothelial papilloma nor urothelial inverted papillom shares the common genetic alterations frequently seen in malignant urothelial neoplasm, which may reflect their favorable prognoses and benign clinical courses; suggesting distinct pathogenetic pathways. However, due to the limited case number (4) of urothelial papilloma included in the previous study, ${ }^{35}$ a further study is warrant to arrive on a conclusion of genetic nature of urothelial papilloma, especially considering the fact that a small portion of urothelial papilloma may recur ${ }^{36}$ or even progress to develop urothelial carcinoma. $^{37}$

The most consistently informative marker of the clonal composition of neoplasm in female subjects is the nonrandom pattern of $\mathrm{X}$-chromosome inactivation. ${ }^{26,29}$ Polyclonal proliferative lesions in female patients are composed of cells with different origins and randomly inactivated X-chromosomes will be identified within them, while neoplasms arising from a single clone are composed of cells in which 
the same X-chromosome is inactivated. ${ }^{26,29,38,39}$ In our study, one inverted papilloma showed nonrandom inactivation of $\mathrm{X}$-chromosomes, suggesting that inverted papillomas arise from a single progenitor cell and supporting the clonal process of inverted papilloma.

\section{References}

1 Eble JN, Sauter G, Epstein JI, et al. Pathology and Genetics of Tumours of the Urinary System and Male Genital Organs. IARC Press: Lyon, 2004, pp 114-115.

2 Asano K, Miki J, Maeda S, et al. Clinical studies on inverted papilloma of the urinary tract: report of 48 cases and review of the literature. J Urol 2003;170: 1209-1212.

3 Broussard JN, Tan PH, Epstein JI. Atypia in inverted urothelial papillomas: pathology and prognostic significance. Hum Pathol 2004;35:1499-1504.

4 Cheon J, Kim HK, Kim JJ, et al. Malignant inverted papilloma of the urinary bladder: the histopathological aspect of malignant potential of inverted papilloma. J Korean Med Sci 1995;10:103-110.

5 Cheville JC, Wu K, Sebo TJ, et al. Inverted urothelial papilloma: is ploidy, MIB-1 proliferative activity, or p53 protein accumulation predictive of urothelial carcinoma? Cancer 2000;88:632-636.

6 Lazarevic B, Garret R. Inverted papilloma and papillary transitional cell carcinoma of urinary bladder: report of four cases of inverted papilloma, one showing papillary malignant transformation and review of the literature. Cancer 1978;42:1904-1911.

7 Renfer LG, Kelley J, Belville WD. Inverted papilloma of the urinary tract: histogenesis, recurrence and associated malignancy. J Urol 1988;140:832-834.

8 Stein BS, Rosen S, Kendall AR. The association of inverted papilloma and transitional cell carcinoma of the urothelium. J Urol 1984;131:751-752.

9 Urakami S, Igawa M, Shirakawa $\mathrm{H}$, et al. Biological characteristics of inverted papilloma of the urinary bladder. Br J Urol 1996;77:55-60.

10 Witjes JA, van Balken MR, van de Kaa CA. The prognostic value of a primary inverted papilloma of the urinary tract. J Urol 1997;158:1500-1505.

11 Baud E, Catilina P, Boiteux JP, et al. Human bladder cancers and normal bladder mucosa present the same hot spot of heterozygous chromosome-9 deletion. Int J Cancer 1998;77:821-824.

12 Czerniak B, Chaturvedi V, Li L, et al. Superimposed histologic and genetic mapping of chromosome 9 in progression of human urinary bladder neoplasia: implications for a genetic model of multistep urothelial carcinogenesis and early detection of urinary bladder cancer. Oncogene 1999;18:1185-1196.

13 Keen AJ, Knowles MA. Definition of two regions of deletion on chromosome 9 in carcinoma of the bladder. Oncogene 1994;9:2083-2088.

14 Louhelainen J, Wijkstrom H, Hemminki K. Multiple regions with allelic loss at chromosome 3 in superficial multifocal bladder tumors. Int J Oncol 2001;18: 203-210.

15 Miyao N, Tsai YC, Lerner SP, et al. Role of chromosome 9 in human bladder cancer. Cancer Res 1993;53:40664070 .
16 Orlow I, Lacombe L, Hannon GJ, et al. Deletion of the p16 and p15 genes in human bladder tumors. J Natl Cancer Inst 1995;87:1524-1529.

17 Orntoft TF, Wolf H. Molecular alterations in bladder cancer. Urol Res 1998;26:223-233.

18 Primdahl $\mathrm{H}$, von der Maase $\mathrm{H}$, Christensen $\mathrm{M}$, et al. Allelic deletions of cell growth regulators during progression of bladder cancer. Cancer Res 2000;60: 6623-6629.

19 Sidransky D, Von Eschenbach A, Tsai YC, et al. Identification of p53 gene mutations in bladder cancers and urine samples. Science 1991; 252:706-709.

20 Brandli DW, Ulbright TM, Foster RS, et al. Stroma adjacent to metastatic mature teratoma after chemotherapy for testicular germ cell tumors is derived from the same progenitor cells as the teratoma. Cancer Res 2003;63:6063-6068.

21 Cheng L, MacLennan GT, Zhang S, et al. Laser capture microdissection analysis reveals frequent allelic losses in papillary urothelial neoplasm of low malignant potential of the urinary bladder. Cancer 2004;101: 183-188.

22 Kernek KM, Ulbright TM, Zhang S, et al. Identical allelic losses in mature teratoma and other histologic components of malignant mixed germ cell tumors of the testis. Am J Pathol 2003;163:2477-2484.

23 Paterson RF, Ulbright TM, MacLennan GT, et al. Molecular genetic alterations in the laser-capturemicrodissected stroma adjacent to bladder carcinoma. Cancer 2003;98:1830-1836.

24 Uchida A, Tachibana M, Miyakawa A, et al. Microsatellite analysis in multiple chromosomal regions as a prognostic indicator of primary bladder cancer. Urol Res 2000;28:297-303.

25 Cheng L, Shan A, Cheville JC, et al. Atypical adenomatous hyperplasia of the prostate: a premalignant lesion? Cancer Res 1998;58:389-391.

$26 \mathrm{Gu}$ J, Roth LM, Younger C, et al. Molecular evidence for the independent origin of extra-ovarian papillary serous tumors of low malignant potential. J Natl Cancer Inst 2001;93:1147-1152.

27 Cheng L, Song SY, Pretlow TG, et al. Evidence of independent origin of multiple tumors from patients with prostate cancer. J Natl Cancer Inst 1998;90: 233-237.

28 Cheng L, Gu J, Eble JN, et al. Molecular genetic evidence for different clonal origin of components of human renal angiomyolipomas. Am J Surg Pathol 2001;25:1231-1236.

29 Katona TM, Jones TD, Wang $\mathrm{M}$, et al. Molecular evidence for independent origin of multifocal neuroendocrine tumors of the enteropancreatic axis. Cancer Res 2006;66:4936-4942.

30 McCarthy RP, Wang M, Jones TD, et al. Molecular evidence for the same clonal origin of multifocal papillary thyroid carcinomas. Clin Cancer Res 2006;12:2414-2418.

31 Cheng L, Jones TD, McCarthy RP, et al. Molecular genetic evidence for a common clonal origin of urinary bladder small cell carcinoma and coexisting urothelial carcinoma. Am J Pathol 2005;166: 1533-1539.

32 Cheng CW, Chan LW, Chan CK, et al. Is surveillance necessary for inverted papilloma in the urinary bladder and urethra? Aust NZ J Surg 2005;75:213-217.

33 Amin MB, Gomez JA, Young RH. Urothelial transitional cell carcinoma with endophytic growth 
patterns: a discussion of patterns of invasion and problems associated with assessment of invasion in 18 cases. Am J Surg Pathol 1997;21:10571068.

34 Junker K, Boerner D, Schulze W, et al. Analysis of genetic alterations in normal bladder urothelium. Urology 2003;62:1134-1138.

35 Chow NH, Carins P, Eisenberger CF, et al. Papillary urothelial hperplasia is a clonal precursor to papillary transitional cell bladder cancer. Int J Cancer 2000;89: $514-518$
36 Cheng L, Darson M, Cheville JC, et al. Urothelial papilloma of the bladder: clinical and biologic implications. Cancer 1999;86:2098-2101.

37 Magi-Galluzzi C, Epstein JI. Urothelial papilloma of the bladder. A review of 34 de novo cases. Am J Surg Pathol 2004;28:1615-1620.

38 Nowell PC. The clonal evolution of tumor cell populations. Science 1976;194:23-28.

39 Vogelstein B, Fearon ER, Hamilton SR, et al. Clonal analysis using recombinant DNA probes from the X-chromosome. Cancer Res 1987;47:4806-4813. 